\title{
Rococó, neoclasicismo y prerromanticismo en la poesía española del siglo XVIII
}

\author{
por JoAquin ARCE FERNANDEZ \\ Catedrático de la Univeroidad de Madrid
}

1.-El siglo XVIII sigue preocupando a la crítica literaria. Preocupación que se suele manifestar en unas palabras, ya tópicas, sobre la complejidad, importancia y significación de dicha época, que contrastan con el olvido en que se la tiene. Pero lo curioso es que desde hace más de cien años se viene repitiendo lo mismo. ${ }^{1}$

El punto clave de las discusiones y de la disconformidad es la poesía de entonces, sin vibración comunicativa para la sensibilidad de nuestro siglo, por la futilidad de sus temas en unos casos o por su pretensión

1. «...El stglo XVm, uno do los mís insignes en la historia del mundo, no porque en él haya dado quizá la literatura frutos tan sazonados como dio en el siglo anterior, y aun en el siglo XVI, sino porque en èl reciblo el enteridimiento humano un impulso violento y se precipitó a la vez por varias sendas, sin apartarse empero de la literaria, viene por oso a ser la época más importante quizá en la historia del limaje humano, es decir, en la historia de los progresos del humaro entendimiento". (A. Alcalá Galiano, Historia de la Literatura Españota, Francesa, Inglesa, Ltatiana. on el siglo XVIII, Madrid, 1844, pág. 7.)

*El siglo xvirr tal como fue, tal como lo hicieron las leyes providenciales de la historia, es digno de profundo estudio en todas sus manifestaciones morales, políticas y literarias» (Leopoldo Augusto 
de trascendencia elocuente en otros. A la escasez corresponde una abundante producción en verso, mente como instrumento de mera comunicación es discursivo a lo familiar. Tan ligados se dan ento intelecto y del sentimiento que no es posible desli $Y$ el binomio sentimiento-razón, en oposición dram esfuerzo conciliador, estará en la base de las comp lectuales $o$ artísticas, del siglo.

Es necesario replantear el estudio de las tendt centistas para llegar a una precisa determinación de en cuenta, con ciertos límites, propuestas afines de reciente crítica literaria italiana, ${ }^{2}$ adaptadas a las liares de nuestra literatura dieciochesca. Se abren c bilidades interpretativas y nuevos enfoques críticos futuro estudios más centrados, más monográficos, taculizar una visión de conjunto, como la presente, sional y epidérmica.

2.-La poesía española del siglo XvirI no se nos pı masa monótona y monócroma ni como una sucesi escuelas o tendencias. Lo que se entiende normaln es producción casi exclusiva de su segunda mitac sucesiva de poetas diversos, pudiera recibirse la imp cronológicas -en realidad inexistentes- entre ur afirmarse, sin grandes posibilidades de error, que en viven o coinciden todas las corrientes o actitudes $p$ rizan al siglo XvirI. No se trata por el momento de r

de Cueto, Bosquejo histórico-crítico de la poesía castellana en el siglo $X$ gina $\mathrm{CXXXVI)}$

«Aquel siglo [eI XVIII], tan ceremonioso y tranquilo en la superficie; ta fondor (M. Menéndez Pelayo, Estudios y Discursos de critica histórica y t. IV, pág. 321).

a Por la libertad en el pensar, por el análisis en el sentir y por las duda namente hijos del siglo xvir. (Alfonso Par, Shakespeare en la literatura 1935, t. I, pág. 57)

"... Nuestro siglo XVII, til menos brillante de la liferatura española, pero porque en él se inksio un giro, dosvioción radictil parat algunos, del que nace modernas (Angel del Rio, Jotathosos. Obras cscogiwia, Madrid, Espasa-Ca]

aEl siglo XVIII compienza a ses stmpation; ventss en esa centuria Io que r a tal centuria más atención que antes" (Azorín, "El siglo XviI", en $A . B$.

2. Me netiero, sobre todo, a Walter Binni, que abordo al tema $I /$ Rococo internazionale del año 1960, del que se recogierop las pomencias y discusir rismo, Banocio, Racped: concette e termini. Roma, Aceademia Nazionale di de Binn, pubsicato antoriormente en La Rassegnis datla Letteratura fratiana; incorporado al volumen Classicismo e Novelassicismo tictla fetteratara det
Nuova Italia, 1963 . 
esas corrientes, sino de distinguirlas y constatar su presencia. Debe evitarse el encasillar rígidamente en fórmulas prefabricadas a los distintos escritores, pero no deben echarse en olvido los motivos de gusto, de estilo o actitud que permiten aproximar o separar sensibilidades distintas. El último trentenio del siglo se define por su fervor intelectual, por sus inquietudes. A pesar de su intención satírica, bien lo definió Leandro Fernández de Moratín:

$$
\begin{aligned}
& \text { y este celo, y esta } \\
& \text { comezón docta, es general locura } \\
& \text { del filosofador siglo presente. }{ }^{3}
\end{aligned}
$$

En esta inquieta búsqueda, en este - valga la expresión- enciclopedismo sentimental, las corrientes poéticas, indicio de sensibilidades diversas, pueden coincidir, y de hecho coinciden, en el mismo autor. La cultura literaria de entonces amalgama los nombres más dispares: junto a Anacreonte, Píndaro; junto a Garcilaso y Villegas, Fray Luis o Herrera; junto a Milton y Young, Rousseau y Gessner; junto a Metastasio, Alfieri. Naturalmente, estas autoridades literarias definen corrientes discriminadas. Pero lo característico es, quizá, su presencia conjunta. A cierta evolución en las preferencias se puede aludir, aunque siempre en términos muy generales: en la simpatía por los autores del siglo XVI, se puede observar que la predilección por Garcilaso y Villegas se va sustituyendo por la de Fray Luis y Herrera conforme se afianza la sensibilidad prerromántica; en el influjo de las naciones extranjeras modernas, a Francia, Inglaterra e Italia, respectivamente, podría asignárseles la inclinación, no netamente decidida desde luego, de los poetas afiliables a la Ilustración, al prerromanticismo y al neoclasicismo. Consideraciones estas que, por su misma vaguedad, carecen de valor absoluto. Más concretamente puede afirmarse que muchos autores, muchos temas o motivos llegan a interpretarse, a sentirse de modo distinto al suyo originario. $\mathrm{Y}$ esta tonalidad característica, y no el tema o dato en sí, es lo que puede justificar su inclusión en una u otra corriente. No pueden formarse grupos o etapas de insalvables contornos; pero sí pueden clasificarse tendencias y actitudes por el modo peculiar de sentir y transmitir el tema. Todos, o casi todos los elementos que componen la poesia setecentista están ya en la misma tradición literaria española. Un género tan convencional, tan tradicional como la égloga, arrastra consigo una añeja carga de blando sentimentalismo y unas invocaciones directas a la naturaleza que pueden fácilmente acordarse con la sensi-

3. A Claudio. El filosofastro, BAE, t. II, p. 586. 
bilidad prerromántica. Una forma estrófica tan típicamente dieciochesca como la octavilla en agudos, que Metastasio emplea en la mórbida languidez melódica de sus arias, se ha de convertir en España, a través de sus semiolvidados precedentes prerrománticos, en estrofa característica del romanticismo. Y una muestra bien significativa de fusión o confusión prerromántica la tenemos en el Saúl de Francisco Sánchez Barbero, ${ }^{4}$ donde la frívola elegancia de las formas metastasianas se convierte en vehículo de la exaltada turbulencia de un tema y de un carácter "protoromántico", para usar la calificación que a Alfieri aplicaba Croce.

3.- - Lo cierto es que en la producción poética del siglo xvirr español se da como normal la coexistencia en el mismo autor de una poesía de alcance limitado, de tono personal y modesto, junto a una poesía de elevadas pretensiones didácticas, sociales o filosóficas. Usando términos muy de hoy, puede constatarse la presencia, casi simultánea, de una literatura de evasión al lado de una literatura comprometida. Esa constatación, pues, de carácter general, no debe prejuzgar la inclusión de un poeta en una determinada tendencia.

Aun cuando no se trate de deslindar escuelas o grupos con códigos determinados, conviene separar y clasificar las maneras de reaccionar ante los probleinas de la cultura o del arte. No son, por sí mismos, cánones, ternas o formas los que deciden la clasificación: es cuestión de preferencias, de insistencia, de tonalidades características, de vibración personal. Sin embargo, si ideas y sentimientos no han estado nunca tan unidos como en el siglo XVIII, necesaria es también otra caracterización que se quede en el plano de lo meramente ideológico; y a esta poesía, que expresa su admiración ante la ciencia, las instituciones o los ideales contemporáneos es a la que puede asignarse el nombre de "poesía de la Ilustración». Es precisamente en el ambiente poético de la Ilustración donde se van forjando, desde mediados de siglo en adelante, las dos direcciones fundamentales que se plasmarán, después de 1770, en el Prerromanticismo y en el Neoclasicismo.

4.- Dentro de la actitud clasicista y racionalista que caracteriza al siglo XVIII y parte del siguiente, desde Luzán a Quintana, conviene delimitar el verdadero impulso neoclásico de fines de siglo, que tiene caracteres bien definidos de carácter expresivo y formal, aunque sus

4. Saúl, melodrama sacro en dos actos, BAE, t. 63, ps. 633-641. La obra, puesta en música, fue representada en 1805. La intención primera del autor, según él mismo confiesa, fue traducir el original alfieriano, pero después actú por su cuenta. Los monólogos recuerdan a Alfieri; las arias metastasianas y los coros injertados son, en cambio, lo más opuesto a la técnica del gran trágico italiano. 
estímulos inmediatos coincidan en gran parte con el coetáneo movimiento prerromántico. Si Neoclasicismo es Winckelmann, Mengs, David, Canova, Chénier y Foscolo, sólo una poesía que corresponda a idénticos y elevados ideales estéticos debe considerarse tal. Fue, creo, la historiografía literaria española de fines del Ochocientos la que empezó a englobar, bajo el equívoco nombre de Neoclasicismo, a todas las corrientes clasicistas del siglo XVIII. Sin embargo, los contemporáneos o los inmediatamente posteriores tuvieron clara conciencia de la diversidad de tendencias. Por eso Quintana distinguía el "gusto extraño, que parece tomado del francés, del alemán y del inglés" de aquellos otros que «han preferido la imitación italiana», caracterizando formalmente a estos últimos, los neoclásicos, por «su esmero en la puntual simetría de los metros, en el halago de los números, en la elegancia y pureza del estilo, en la facilidad y limpieza de la ejecución». Y Alcalá Galiano señalaba, refiriéndose a 1806, dos bandos literarios en los que inflúan también sus ideas políticas, religiosas y sociales. Parece insinuarnos con ello la existencia de un arte oficial, patrocinado por Godoy y encabezado por Leandro Fernández de Moratín, que era amante de la autoridad y no de la libertad política, "clásico en su gusto, esto es, a la latina o a la francesa». El otro bando era de ideas revolucionarias, de un clasicismo «menos puro», representado por Quintana y Cienfuegos. ${ }^{5}$

Quien vio, sin embargo, con claridad inusitada a lo largo del siglo $\mathbf{x x}$, los flujos y reflujos de la sensibilidad literaria de fines del Setecientos, fue F. Bertrán y de Amat, en un opúsculo injustamente semiolvidado. $\mathrm{Su}$ interpretación puede ser hoy compartida plenamente. No sólo dio el nombre que les corresponde a esas

«dos corrientes en que se bifurcó el gusto artístico al comienzo de este siglo [el $\mathrm{xIX}]$, o sea la restauración clásica... y el nacimiento de la escuela romántica»,

sino que intuyó en la verdadera restauración neoclásica una de las fuerzas que coadyuvaron al triunfo del romanticismo:

"Así, pues, en las doctrinas de Winckelmann, "el más famoso de los críticos del arte", ha de reconocerse una emancipación del gusto francés que precede muy de cerca a la que produjo el movimiento en las ideas de que me ocupo, el origen del sentido crítico que caracterizó la primitiva escuela romántica, y una base sólida en que fundar las doctrinas de la misma.»

5. M. J. Quintana Poesías selectas castellanas, Madrid, 1830, t. IV, p. XLVIII. A. Alcalá Galiano, Recuerdos de un anciano, Madrid, 1890, ps. 63 y sigs. Con más amplitud trato este punto, donde pueden verse las citas completas en mi estudio aJovellanos y la sensibilidad prerromántica», $B B M P$. 1960, número 2. 
Pero lo que merece destacarse aún más es que distinguió perfectamente en las artes plásticas el Neoclasicismo stricto sensu de las manifestaciones artísticas, también típicamente dieciochescas, que aquí incluiremos en el estilo rococó :

"Aparte del pequeño grupo de pintores de la bourgeoisie, que aspiraban a un arte propio de su tiempo, y de decaídas tradiciones clásicas y del Renacimiento; en la reproducción de fiestas galantes, en las imaginarias escenas pastoriles, en fantásticos paisajes, en la estatuaria para jardines, en las artificiosas cabañas de los parques, buscábase sólo la gracia, una suerte de seducción placentera de los sentidos, algo coquetón, muelle y sensual, no falto ciertamente de atractivos, aunque escaso de verdad y aliento. Enfrente de este arte cortesano se levantó la escuela del pintor David, que ejerció grandísima influencia por sus cuadros y como preceptor excelente. Afiliado a la restauración del clasicismo, promovido en Alemania por Winckelmann e interpretado por Mens [sic], Canova y Vignon, aunque con frecuencia dejó transparentar en sus cuadros las pasiones de los turbulentos tiempos en que viviera, afanoso de imprimirles el gusto griego, dio conscientemente a sus figuras la inmovilidad marmórea de las estatuas y a la composición el convencionalismo a que, a su parecer, debió de ajustarse la pintura helénica.»6

5.-Hoy por hoy no puede hablarse en la literatura española de una época ni siquiera de una tendencia bien delimitada de tipo rococó. Sin embargo, esa denominación parece insustituible para distinguir, precisamente por contraste, ese tono menor, elegante y frívolo de la poesía dieciochesca, siempre que vaya cargado del espíritu del siglo. Poesía que casi coincide cronológicamente con la típica de la Ilustración, en su forma discursiva de exaltación de asépticos ideales o en la forma clasicista de magnificencia mitológica, alcanzando en parte también Ia bifurcación neoclásico-prerromántica de fines de siglo.

No parece oportuno en nuestro caso, como dice el citado Walter Binni de la literatura de su país, hablar del rococó como de todo un estilo de época. Pero tampoco conviene reducirlo, como hace el crítico italiano, a un mero "componente di gusto", ni llegar, dado el estado de los estudios sobre poesía española en el siglo XVIII, a las matizaciones excesivas que él atribuye a la poética del Settecento. En España ni existe un término comprensivo, como el de la Arcadia setecentista, que engloba en la literatura italiana toda la producción poética de la primera mitad del siglo, con sus direcciones de Arcadia petrarquista, pastoral, anacreón-

6. F. Bertrán y de Amat, Del origen y doctrinas de la escuela romántica y de ta participación que tuvieron en el adelantamiento de las Bellas Letras en Barcelona los señores D. Pablo y D. Manuel Milá y Fontanals y D. Claudio Lorenzale, segunda edición, Barcelona, Gustavo Gili, 1908. 
tica, clasicizante y lúgubre, ni puede sustituírselo, como hace Binni, con sus personales matizaciones: classicismo arcadico-rococò, classicismo sensistico-rococò, poetica illuministica-sensistica-classicistica de Parini, etcétera. La situación de los estudios españoles sobre la poesía del siglo xviII no permite estos refinamientos caracterizadores que resultarían confusos y atomizarían con exceso lo que, equivocadamente también, se suele ver como un bloque. Util, en cambio, se muestra el término "rococó» como indicativo de una modalidad poética que es reflejo de un gusto figurativo, de una moda y unas costumbres. Y creo conveniente utilizarlo, por el momento, no sólo como simple elemento componente de poéticas más complejas, sino como el aspecto unificador de toda una serie de corrientes entrecruzadas - bucolismo, anacreontismo, sensualismo, etc.- en la medida en que todas ellas, aun sin ser originales, responden a actitudes peculiares de la vida y de la cultura dieciochescas.?

6.-En 1737 se publica la primera edición de la Poética de Luzán. La base estética de la actitud clasicista, típica del siglo, está ya en esta obra. Sin embargo, en esta primera edición, tuvo escaso influjo, pues apenas fue leída y tenida en cuenta por los escritores de mediados de siglo. ${ }^{8}$ La poética que ha de responder, en cambio, a los ideales del último cuarto del siglo serán las Investigaciones filosóficas sobre la Belleza Ideal, de Esteban de Arteaga, que funde, en 1789, principios y elementos derivados de sistemas diversos, en una personal síntesis de estética neoclásica. Lo que idealmente une a Luzán y a Arteaga es su atención hacia Italia, en la que ambos vivieron.

El espíritu crítico del siglo, el afán educador y el saber enciclopédico los resume el padre de los ilustrados españoles que fue Feijoo. Aquí podría interesarnos tan sólo su repercusión en la sensibilidad literaria de la época, que fue prácticamente inexistente. Ahora bien, es hora de valorar justamente el alcance estético de su tratado sobre $E l$ no sé qué, considerado habitualmente por la crítica española como un ensayo pre-

7. Comparto, pues, plenamente, en el ispecto literario, la opinión de Georg Weise en «L'Italia e Il problema delte origini del Rococoss, Paragone (Arte), 1954, nủm. 49, pág. 37: Finvece che un mutamento fordamentale del patrimonio stilistico il Rococos significa piuttosto il momento in cut gli stessi tradizionali olementi formali divengono più gracili, piû duttili e piegheveli, piô movimentatí e meno ridondanti; ma senza che le nuove tendenze si intreccino in modo nettanente sceverabile dalla persistenza dellorientamento classico-eroicheggiante che sopravvive fino al neo-classicismo, col quale si chiude in definitiva l'et̀̀ storica ed artistica iniziata dall'umanesimo e dal Rinascimento.»

8. «En vano el benemérito don Ignacio de Luzán quiso estimular a sus conciudadanos con la doctrina y el ejemplo. Su Poética, impresa ex el año de 1737, no se léa en el de 1760, y sus composiones tiricas, en que celebrs los esfuerzos que empezaron a hacer las bellas artes, se oyeron con privado aplauso en la academia de San Fernando; pero no sirvieron de otra cosa que de abultar los cuadernos de sus actas (Vida de don Nicolás Femández de Moratín, escrita por su hijo Leandro, en BAE, t. II, p. VIII). 
cursor de los ideales del siglo xIx. Fue Menéndez Pelayo, sobre todo, quien lo valora, con exageración evidente, como un «verdadero manifiesto romántico», reconociendo paradójicamente «en este romanticismo anticipado, el último fruto de la antigua crítica española».9

Reléanse, antes de aceptar unos juicios tan pasivamente repetidos, algunas frases típicas del tratado feijoniano, citadas por el propio don Marcelino. Habla Feijoo de que en muchas producciones hay un "primor misterioso», que lisonjea «el gusto», que «los sentidos le palpan» y que explicamos como «un no sé qué que agrada, que enamora, que hechiza»; lo mismo quizá que Ios griegos llamaban "gracia». En un rostro humano puede depender de las «innumerables diversísimas combinaciones de las partes»; en los edificios, el "no sé qué de gracia» es "una determinada combinación simétrica, fuera de las comunes reglas».

Feijoo, hombre de su época -y el haberla sabido interpretar sin atisbos proféticos es su gran mérito-, utiliza un vocabulario y unos conceptos, en las frases citadas, en intima conexión con el gusto figurativo caracteristico del segundo tercio del siglo xviII. Alude a estructuras y disposición de partes, a simetrías insólitas y nuevas, a primor, gracia y hechizo, al libre juego de las líneas, típico de las corrientes artísticas derivadas del barroco. Véanse estos versos, que cita también Menéndez Pelayo:

Puede salir la estructura

buena de muchas maneras

$\mathrm{y}$ es el variar de Ias líneas

valentía de la idea.

Libertad estética, sí; pero no parece oportuno hablar de romanticismo, a través de los juicios copiados, a no ser que se deduzcan por propia cuenta las sugestiones que, fuera de su contexto, evoca el no sé $q u e .^{10}$ Es obvio, en todo caso, que, aunque aplicada la frase con distintos sentidos y en diversas épocas, ha sido preferida por las poéticas basadas fundamentalmente en la irracionalidad o inefabilidad.

Por otra parte, tampoco es Feijoo el único que la utiliza en su época. Ya en 1902, Croce dedicaba un breve apartado de su Estética a los que

9. M. Menéndez Pelayo, Historia de las ideas estéticas en España, Ed. Nacional, t. III, ps. $106-114$.

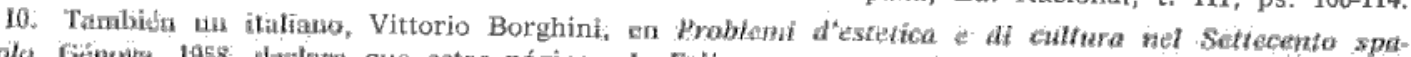
knolo. Génova, 1958, declara que estas páginas de Feljoo -veranerte inagurano in Spagno il Romanti-

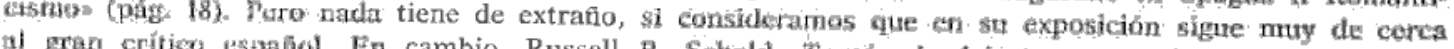

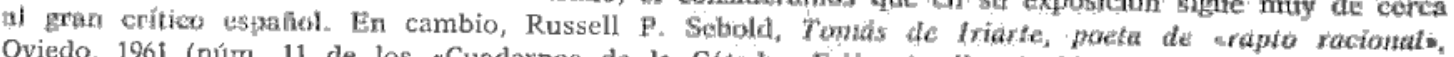
Oviedo, 1961 (núm. 11 de los eCuadernos de la Cátedra Feijoon), dice incidentalmente, refiriendosé i este ensayo de Feijoo, que su egenialidad se ha venido defendiendo con la impropicdod de desiguarlo como prerromántico. (pág. 42). 
ponen el gusto en un non so che, je ne sais quoi, nescio quid, mencionando, con Feijoo, a Montesquieu, a Salvini en las notas a la Perfecta poesia de Muratori y a Bouhours, que, en 1671, considera que esa expresión es empleada continuamente por los poetas italianos. ${ }^{11}$ En efecto, es típica del estilo esfumado de Torquato Tasso; y había sido, por tanto, utilizada a principios del siglo Xviı por Juan de Jáuregui en su famosa y elogiada, aunque no estudiada, traducción del Aminta. El no sé qué, como frase, ha sido rastreado a lo largo de las dos literaturas, la italiana y la española, ${ }^{12}$ aunque en este caso lo que nos interesa es su aplicación a una teoría estética. En la situación actual de nuestros estudios, coincido en gran parte con los resultados de la crítica italiana, tanto en el sentido y alcance que puede darse a dicha expresión en el siglo XVIII, por quien no pensaba en Feijoo al hacerlo, ${ }^{13}$ como con los hispanistas que no han aceptado la interpretación tradicional, en sentido romántico, del ensayo feijoniano. ${ }^{14}$

Descartada la vinculación del no sé qué en el tratado de este título con zonas irracionales del futuro romanticismo y admitiendo que la frase tiene sus raíces en la poesía y en la poética anteriores, hay que reconocer su conexión con el espíritu dieciochesco que llega hasta la mitad del siglo, al valorar ciertos motivos caprichosos y esa gracia misteriosa que desdice de las reglas establecidas. Precisamente en una égloga de José Iglesias de la Casa, ambientada en un cuadro de gráciles elementos de jardinería, emparentados con el gusto rococó, aparece la

11. Benedetto Croce, Estética come scienza dell-espressione e linguistica generale, 9.a ed., Bari, Laterza, 1950, ps. 219-220.

12. Para el español pucde verse la reseña de A. Porqueras Mayo, en RFE, XI.II, 1960, pags. $500-501$, del estudio de Erich Kohler, aDer Padre Féjoo und das no sé qué, en Romanistisches fahrbuch, VII, 1955-56, ps. 272-290. Para la literatura italiana hay dos articulos de Givilio Natali, astoria del nam so chem $\mathrm{y}$ Ancora del nonsoché, ambos en Litgha Nostra, XII, 2, 1951, y XIX, 1, 1958, respectivamente. Si los testimonios aducidos van en Italia desde Dante a principtos del presente sigto, en España van desde Boscán y J. de Valdés a J. R. Jiménez, o - si tenemos en euenta las integraciones de la reseña de Porqueras- desde la Celestina a M. Hernández.

13. Walter Binni, en la breve nota dedicada al primer artículo citado de G. Natali, en Rassegna della Letteratura Italiana, núm. 2, 1960 , p. 341, escribe: all Natali considera il «non so che settecentesco soprattutto "preromanticon: io direi senz'altro metastasiano e arcadico-rococò ben calcolando naturalmente quanto di metastasiano poté confortare (fra sottili venature e ripulse) certa sentimentalità preromantica più italiana e moderata,s

14. Carmelo Samona, «I concetti di gusto e di no sé qué nel Padre Feijoo e la poctica del Muratorin, Giontate stortico della letteratura italiana, CXLI, fasc. 433, 1964. Samona considera que el Feijoo prerrornático hay que corregirio con el que, con fuentes barrocas, siente la tradición de libertad espafiola; señala además la relación entre el ono sé qués y el típico ubuen gustan setecentista, según la nota de Salvini a la Perfetía poesia muratoriana: a. buon gusto \& un nome venuto su nei nostri tempi; pare un nome vagante... che si rimetta al Non so cho." También Mario Di Pinto, en Cuttura stognolit settecento, Napoles, Ediziont Scientifiche Italiane, 1964, señala que con Feijoo astamos siempre en los limites del racionalismo y ahde al equiveco que supone hablar de libertad estetica; incluso la palabra agenios, en Feijoo, debe entenderse wella nozione di intelletto e di guste, non di fantasia= (pág. 146). 
expresión feijoniana, aplicada al rapto misterioso de la mente ante la hermosura natural:

\author{
En este sitio, de sin par belleza, \\ y en sumo grado ameno y delicioso, \\ tanto, que mi atención lleva a la alteza \\ de un no sé qué divino y venturoso; \\ que cierto aquí extremó naturaleza \\ todo lo más suave y más hermoso...15
}

7.-Sabido es que la poesía de la primera mitad del Setecientos vive a expensas de las últimas derivaciones de la literatura barroca. Si la norma ideal de toda la centuria será el «buen gusto», estos primeros poetas tendrár todavía lo mejor de su producción en las formas literarias que son consecuencia del "mal gusto» seiscentista. De todos modos, este gongorismo dieciochesco se ha templado. Las metáforas, la lengua y la estructura del verso siguen siendo gongorinas. La sintaxis, en cambio, a no ser en construcciones ya congeladas, ha debilitado, y mucho, su audacia latinizante. No me corresponde aludir en conjunto a estos poemas mitológicos, que no merecen el olvido en que se les tiene, en parte remediado recientemente por Cossío y Glendinning; ${ }^{16}$ pero sí me parece necesaria una referencia a José Antonio Porcel, a quien puede situarse en el momento de paso de la grandiosidad técnica barroca a la ligereza rítmica del rococó. Casi mediado el siglo, a los veintitantos años, escribió su poema mitológico Adonis. Han pasado unas décadas desde que en $1718 \mathrm{~J}$. León y Mansilla ha publicado su Soledad tercera. El estilo gongorino se atenúa en Porcel con el recuerdo constante de Garcilaso. Pero, a ratos, se percibe cierto empequeñecimiento del escenario $\mathrm{y}$ de los elementos que lo componen, una interpretación agraciada y modulada que lo alejan del macizo sentido constructivo del barroco. La cuna granadina del autor podría hacernos pensar en ese primor que es característico del arte local. En todo caso, aquí nos interesa ver su posible relación con ese barroco en miniatura, de formas gentiles, que en el arte italiano se llama «barocchetto» y va transformándose en rococó. Comparemos los versos de Góngora, donde quizás utiliza por primera vez en la lengua poética española el adjetivo bipartido, ${ }^{17}$ con los pasajes en que lo emplea Porcel. La concentrada sintaxis gongorina, al referirse al raro animal sardo, el muflón («sin dejar ni aun pequeña

15. Egloga VIII, BAE, t. 61 , p. 458.

16. José Maria de Cossio, Fábulas mitológicas en España, Madrid, Espasa-Calpe, 1952. Nigel Glendinning, "La fortuna de Góngora en el siglo xviun, RFE, XLIV (1961), 3.0-4.

17. Cfr. Joaquín Arce, «El muflón sardo en unos versos de Góngora: dificultades de interpretación * $R F E$, t. XLV, 1962. 
( del pie ligero bipartida seña"), se distiende con morbidez y voluptuosidad en notas de blancura, en su imitador dieciochesco:

En tanto que ella, o con la blanca mano, o con el suave aliento del clavel bipartido de su boca, enjuga blandamente del bello joven la sudosa frente.

$\ldots \ldots \ldots . . . .$.

La orgullosa garganta del grueso y ancho pecho se levanta, la que suben formando cándidas roscas de alabastro blando; la barba, hermosamente bipartida, deseos incitaba, porque aún no es de la edad oscurecida.

Véase también un cuadrito mitológico, en el que se añade lo infantil a la complacencia femenina y sensual de los detalles:

Niño, pues, en sus brazos regalado tal vez le tiene la Ericina diosa, y él con la tierna mano cariñosa y gestos halaguieños, vagando de su pecho por la nieve y por la cara hermosa, en la boca, de dulce risa llena, tal vez la detenía, como que sus caricias pretendía.

Licencioso se atreve con los dedos pequeños a asirle a Venus los purpúreos labios; y ella, aunque diosa, de su mal ajena, con ambiciosos besos lo fatiga; porque así dulcemente lo castiga los atrevidos, que apetece, agravios...18

Otras expresiones del mismo poema que, aisladas del contexto, pudieran parecer lejanamente prerrománticas —el impulso trágico, cierta violencia expresiva, los «funestos cipreses»— están meramente en función de ese decorativismo fantástico.

Más directamente asignable al espíritu del rococó es su Epitafio a una perrita llamada Armelinda, donde las reminiscencias clásicas adquieren un nuevo tono, por su elegancia de sinuosas líneas, el mimo casi infantil, sus diminutivos acordes con el blando patetismo y su encantadora insignificancia:

18. El Adonis, en cuatro églogas venatorias, BAE, t. 61, ps. 150, 145 y 144 respectivamente. 
Bajo de este jazmín yace Armelinda, perrita toda blanca, toda linda, delicias de su ama, que aún hoy la llora; Ilórala su cama, la llora el suelto ovillo, como el arrebujado papelillo con que jugaba; Ilórala el estrado, y hasta el pequeño can del firmamento. de Erígone olvidado, muestra su sentimiento; solamente la nieve se ha alegrado, pues si yace Armelinda en urna breve, ya no hay cosa más blanca que la nieve. ${ }^{19}$

8.-Aparte de Porcel, representativo de la sensibilidad de mediados de siglo, como nacido hacia 1720 , los demás autores que dan carácter a su primera mitad enlazan con la inmediata tradición, sea en el sentido conceptuoso-moral o heroico-cómico, como Gabriel Alvarez de Toledo, sea en la dirección gongorina, como León y Mansilla, Torrepalma, Bacallar y E. G. Lobo. A Góngora como modelo literario va sucediendo Garcilaso. Garcilaso es para el XviII español lo que es Petrarca para la poesía italiana: el creador de un instrumento poético, de unas formas expresivas, de una mesura sentimental y rítmica, que es sinónima de "buen gusto». Sin embargo, difícilmente la producción poética del siglo se mantiene en un grado medio de mesura y decoro. Lo normal será la alternancia del tono enfático y pretencioso con ese tono menor sin relieve aparente. Junto al alambicado, conceptuoso y gongorino a un tiempo, Eugenio Gerardo Lobo, mantenedor sin embargo de la métrica tradicional, se da la poesía cascra, de cosas y experiencias familiares, que representa Diego de Torres y Villarroel, y la poesía entonada, mitológico-didascálica de Ignacio de Luzán. Aun sin llegar al gusto de la forma por sí misma y a la preocupación por revivir, con empaque sostenido y elegante, el espiritu de la poesía de la antigüedad, que caracterizará al neoclasicismo posterior, la producción en verso de Luzán abre el camino a la tendencia clasicista del Setecientos y señala con su opacidad el paso a la poesía de la Ilustración.

9.-En la década de 1730 a 1740 nacen unos cuantos escritores -Fray Diego González, Nicolás Fernández de Moratín y García de la Huertaen quienes se insinúan ya las nuevas corrientes del siglo. A la doble

19. BAE, t. 61 , p. 171. Es justo consignar que Higinio Capote, en Poetas liricos del siglo XVIII, Zaragoza, Ebro, 1941, situó y juzgó perfectamente este Epitafio, considerándolo «juguete que tiene la gracia de esas piezas menudas del arte del siglo xvir, relojes, grabados, porcelanas, muestra exquisita y ejemplar casi único en la poesía española de divertissement rococós (t. I, pág. 14). 
dirección señalada, grandilocuente y empequeñecedora, pueden adscribirse el anacreontismo y pindarismo de la poesía clasicista del tercer cuarto del siglo, cuyos nombres representativos, aunque no de un modo tajante, podrían ser los de Cadalso, que nace en 1741, y Moratín padre. Actitud poética contrastante manifiestan también V. García de la Huerta y Fray Diego. La del primero es poesía de fuerza sin salirse de la tradición. La estructura del verso, con sus bimembres o trimembres en final de estrofa, es todavía gongorina y efectista, pero el contenido es frecuentemente encomiástico. Lo personal está ausente de esta poesía, que carece de referencias directas; la misma mitología, no funcional, contribuye a la vaguedad, como las alusiones al arte o a los artistas - Fidias, Apeles, Vitrubio- son totalmente genéricas. Se prepara el camino ál Neoclasicismo, pero éste será, en sus descripciones y valoraciones artísticas, preciso y riguroso.

10.-Con Fray Diego González estamos en la restauración, todavía en sentido tradicional, de Fray Luis de León, sin que Garcilaso esté ausente: una vez más se perciben las notas sentimentales y la ligera participación en las bellezas del paisaje, frecuentes entonces; pero no llega a superarse la visión renacentista española, aunque a veces, como típica de la época, pueda notarse cierta inconcluyente frivolidad. Cuando eleva el tono, como en la traducción de los Salmos, nos encontramos en la dirección que lleva, desde Fray Luis a la grandiosidad bíblica del prerromanticismo. Sin llegar a la típica gracia del sensualismo rococó, entra dentro del gusto dieciochesco de tono menor la siguiente miniaturización mitológica, sin abandonar del todo la línea tradicional:

\footnotetext{
Cogiendo andaba flores

Cupido en una selva.

Vido una fresca rosa que la prisión estrecha del capullo rompía, esparciendo bellezas. Cortóla, y en su centro vio una oficiosa abeja.

.........

Tombla por las alas el niño incauto, y ella el aguijón esgrime con tanta violencia, que en uno de sus dedos clavado se lo deja.

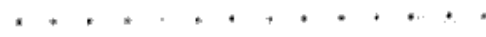

Fue en busca de su madre; y puesto en su presencia,
} 
con tiernos puchericos

le cuenta su tragedia...20

11.-La técnica y los temas del género anacreóntico, por su refinamiento sensual, la despreocupada alegría del vivir, su mitología menor y su ámbito recortado, se adaptaron fácilmente al gusto rococó. La versificación y los asuntos pindáricos, en cambio, responden al «estilo elevado y magnífico", como entonces se decía, en la misma línea del posterior neoclasicismo, que evitará el brillo de las imágenes en beneficio de una mayor rigurosidad de contornos. De Moratín padre a Moratín hijo hay precisamente esta distancia, el paso de lo pintoresco a lo plástico, del brío y garbo de los metros tradicionales que D. Nicolás sintió como pocos en su época, a la versificación robusta e incolora.

Sin embargo, como los encasillamientos rigurosos resultan inadecuados o insuficientes aplicados a los poetas del xvirI, al mismo Moratín padre pertenecen las siguientes estrofas, bien significativas, en las que al señalar a Feijoo como el iniciador del nuevo rumbo científico-filosófico transpirenaico, da unas muestras de lo que fue la poesía ideológica de la Ilustración:

Madrid, la gran Madrid me alimentaba en tiempo tan dichoso, y fue aplaudido sin méritos mi canto; aquí empezaba la ciencia a abrir su alcázar escondido. Vi en él los Malebranches y Bacones, Los Lokes, los Leibnitzes y Neutones.

Feijoo, mi gran Feijoo, las pirineas cumbres pasar los hizo, y ha mostrado el rumbo a solidísimas ideas;

la física a ahuyentar ha comenzado el falso pundonor caballeresco de la nación, y el genio quijotesco. 20 bis

12.-José Cadalso, que abre con su nacimiento el decenio del 40, en que nacerán también Jovellanos e Iglesias, es la primera figura literaria realmente compleja que encontramos en el siglo xviII, situada en el punto de intersección de corrientes diversas. Por esa razón resultan ineficaces todos los intentos de estudiarle desde una sola perspectiva. Creo, con Glendinning, ${ }^{21}$ que no puede interpretarse toda la obra de

20. A la quemadura del dedo de Filis, BAE, t, 61, p. 203.

20 bis. Poema didáctico, BAE, t. II, pág. 65.

21. Nigel Glendinning, Vida y obra de Cadalso, Madrid, Gredos, 1962; y Cadalso, Noches lúgubres, edición, prólogo y notas de N. Glendinning, Madrid, Espasa-Calpe, 1961. Citare por esta última edición. 
Cadalso en sentido romántico o prerromántico. No se trata de ver en él al "primer romántico en acción», como dijo Menéndez Pelayo, porque ni su vida ni su pensamiento pueden ser todavía románticos. Pero ello no es obstáculo para que haya intentado, y conscientemente, adaptarse en un caso concreto a unos modos y a unas modas del sentir completamente nuevos en la literatura española del momento. El "gusto extraño» de origen nórdico, que Quintana señalaba en la poesía de Jovellanos, Meléndez y Cienfuegos, está ya en Cadalso, pero en una obra en prosa. Las Noches lúgubres, escritas inmediatamente después de la muerte de María Ignacia Ibáñez, acaecida en abril de 1771, señalan la introducción, casi de golpe, del estilo prerromántico en la literatura española. Cadalso de muy joven había viajado por Europa, conocía otras lenguas y literaturas. Sin embargo, no se lanza arbitrariamente al nuevo estilo. Es un hecho real, una circunstancia personalísima la que le impele a ello. Esto no quiere decir, naturalmente, que los episodios contados en las Noches sean autobiográficos. Que lo sean o no, nada importa para su caracterización literaria. Sin tener en cuenta lo que de forzado, de retórico, de enfático, lleva consigo el prerromanticismo español, no podrá comprenderse esta consciente literaturización del sentimiento del poeta, ante el hecho incuestionable de la muerte de María Ignacia. Ni la supresión de motivos autobiográficos ni el hallazgo de nuevas fuentes literarias españolas — como la de la leyenda de La difunta pleiteada estudiada por Glendinning - impiden la inserción de las Noches en la poesía lúgubre y sepulcral del prerromanticismo ni el intento de su aclimatación en suelo español. Precisamente, porque hay conciencia de esfuerzo, de rareza, de necesidad de aclimatación, la obra quedó inédita hasta casi veinte años después, cuando ya la sensibilidad había evolucionado. Ni el gusto ni el ambiente español estaban preparados, y el mismo Cadalso reconocerá en sus Cartas Marruecas que se habría atrevido a publicar las Noches, si el cielo de Madrid fuera como el de Londres. ${ }^{22}$

De conceptos y sentencias afines pueden encontrarse precedentes literarios españoles. Lo que no se encontrará es el tema sepulcral con valor autónomo, potenciado, traído a primer plano en ese regodeo morboso y masoquista en torno a la muerte, interpretada sin referencias a la vida eterna, sentida tan sólo con su aparato escenográfico de tumbas y lápidas $\mathrm{y}$ sepultureros y tinieblas y gusanos y pavor y hedor... Y es nuevo el estilo, la preocupación por crear una atmósfera que no sólo

22. «Si el cielo de Madrid no fuese tan claro y hermoso, y se convirtiese en triste, opaco y caliginoso como el de Londres..., me atrevería yo a publicar las Noches lúgubres que he compuesto a la muerte de un amigo, por el estilo de las que escribió el doctor Young. La impresión sería en papel negro con letras amarillas» (Carta LXVII, pág. 226 de la ed. de «La Lecturas, Madrid. 1935). 
depende del típico vocabulario, sino de la resonancia sentimental que producen las buscadas cadencias de esa prosa lenta, distendida y sugerente.

El intento de Cadalso queda aislado, pero que el ambiente está lleno de estímulos semejantes lo demuestra otra obra escrita un año o poco más después. A principios de 1773, tras unas discusiones literarias en la tertulia de Pablo de Olavide, en Sevilla, Jovellanos escribe su obra dramática El delincuente honrado, estrenada y difundida en 1774. En mi opinión, esta obra es el segundo modelo de prosa prerromántica española. No creo que la crítica habitual las haya relacionado nunca en este sentido. Sin embargo, con exacta visión de las cosas, en 1818 se publicó en Burdeos el texto de las Noches, seguido, precisamente, de El delincuente. No es ésta la ocasión de valorar el significado del drama burgués o sentimental, también llamado comedia lacrimosa o patética, en la historia del prerromanticismo. Pero sí es necesaria una alusión a su estilo, junto con el de las Noches lúgubres, por el peso que han tenido en la evolución del lenguaje poético prerromántico.

El esfuerzo por acomodarse a un nuevo instrumento expresivo portador de unos estados de ánimo que deben ser transmitidos sin perder su fuerza de evocación sentimental, es la causa del énfasis retórico del estilo prerromántico. Su cauce más apropiado será el diálogo dramático o la forma lírica de invocación o confesión. Lo importante es que el poeta o el personaje puedan no sólo comunicar sino gritar o susurrar. La acumulación de las figuras retóricas llamadas de sentimiento, bien previstas en los tratados de Poética, producen la rebuscada conmoción. La forma dialogada o monologada de las Noches impiden toda intromisión del autor; y en algunos casos es la explicación del personaje la que sustituye el gesto o acción, que podría haberse encomendado a la mera acotación teatral:

«El es, sin duda: se acerca: desembózome; y le enseño mi luz»...

«Lo que te espanta es tu misma sombra con la mía. Nacen de la postura de nuestros cuerpos respecto de aquella lámpara.»

En su reciente edición de las Noches ya mencionada, señala Glendinning, a quien se los indicó un colega, la «serie de endecasílabos» de esta prosa. Ya en 1960, refiriéndome al Delincuente honrado, al tratar de Jovellanos y la sensibilidad prerromántica, había notado yo mismo que "son frecuentes los endecasílabos y los periodos rítmicos que se repiten" en esta prosa; y con los "personajes exacerbados y efectistas» insistía en el «estilo conscientemente rítmico, mórbido, lánguido». No 
sólo se trata, pues, volviendo al texto de las Noches, de endecasílabos del tipo "todo se inunda en llanto..., todo tiembla", sino también de grupos fónicos octosilábicos en posición relevante («le espantará este aparato», "las dos están al caer») o de heptasílabos paralelos ("el lecho conyugal, teatro de delicias») o de pies métricos de tres o cuatro sílabas que surgen a menudo en breves intervalos: «El cielo / también se / conjura...», "Cubrílos / de polvo, / cenizas, / gusanos / y podre». ${ }^{23}$ Los grupos tetrasilábicos como "el silencio / pavoroso / interrumpido", "He enterrado / por mis manos / tiernos niños", alcanzan su máxima distribución rítmica en las frases siguientes:

que he regado - tantas veces - con mi llanto, y besado - tantas veces - con mis labios.

Todos estos ejemplos, análogos a los recursos expresivos de $E l$ delincuente, pertenecen a las primeras páginas de la primera Noche. Y véanse otra serie de equivalencias tonales y sentimentales entre ambas obras, basadas en conceptos afines: las lágrimas, hiperbólicamente manifestadas; el corazón como órgano del sentimiento y fuente de presagios; el cielo como destino superior:

\section{Noches}

Ya piso la losa que he regado tantas veces con mi llanto.

Mejor que tu boca me lo dice, me lo dice tu corazón.

Por extraño camino me concede el cielo lo que le pedí.

\section{Delincuente}

Al punto me postré a sus pies y los inundé con abundoso llanto.

¡Ay, mi corazón me anunciaba esta desgracia!

El cielo me ha condenado a vivir en la adversidad.

Al mismo tipo de expresión entrecortada y afanosa, con sus puntos suspensivos sugeridores, sus apóstrofes, interrogaciones, exclamaciones, anáforas, conduplicaciones y paralelismos, pertenecían, sin duda, las obras perdidas de Meléndez Tristemio, diálogos lúgubres en la muerte de su padre y Mis pensamientos o reflexiones de un solitario. La prosa prerromántica, artificiosamente poética, no puede ser olvidada, como lo ha sido hasta ahora, en el estudio histórico de la poesía del prerromanticismo español.

23. Un ritmo idéntico lo he sefialado en Jovellanos en mi artículo citado. Ya los contemporáneos se dieron cuenta. J. L. Munárriz, el traductor de Hugo Blair, Lecciones sobre la Retórica y las Bellas Artes, Madrid, 1781, el breviario de los prerrománticos espafioles, objeta sin convicción a la prosa «poética» del Delincuente ael ser en ocasiones demasiado periódica» (t. IV, p. 334). Compárese, además, con el siguiente ejemplo tomado del modelo más acabado de la prosa prerromántica italiana: *...e sono fuggito per non ridestarla alla vita angosciosa in cui geme» (Hugo Fóscolo, Ultime tettere di lacopo Ortis, carta del 12 de mayo). 
Los adjetivos pertenecientes a la esfera de lo lúgubre, funeral, funesto, fúnebre, se ponen de moda. Sin embargo, todos ellos existían ya. Es su intensificación y su nueva intención lo que les caracteriza. Véase la extensión que el mismo Cadalso hace de lúgubre: aplicado a personas, lugares o fenómenos, nada tiene de nuevo: referido a cosas, tuvo que resultar un tanto inusitado: «El vestido lúgubre, las piernas desnudas», "Púseme el vestido más lúgubre».

13.-No obstante la consciente inmersión en la moda prerromántica, Cadalso significó cosa bien distinta en su época. No veo inconveniente para que, por su obra en verso, se le considere -como hicieron sus contemporáneos y discípulos- maestro de la dirección anacreóntica y ligera, ya avanzada la segunda mitad del siglo. El mismo, con sus modelos - Anacreonte, Ovidio, Catulo, Tasso, Garcilaso y Lope- nos declara varias veces su intención y su ideal poético, que le sitúan efectivamente en la dirección contraria a Jovellanos. Su «blando numen», su «tono suave», no pretenden medir "cuánto anda el astro que preside el día», ideal científico característico de la poesía de la Ilustración, ni pretende tampoco cantar

el guerrero rigor, grato al oído del que entre sangre, robo, rapto y furia, a la infeliz humanidad injuria,

ya que, según confiesa,

mi lira canta la ternura sola;

Apolo me la dio, Venus templóla.24

Y es indudable que su poesía está más cerca de un templado anacreontismo rococó que del clasicismo pindárico, el cual, por su elocuencia formal adaptada a nuevos contenidos, lleva a la Ilustración y al Neoclasicismo.

Dentro de la poesía de tono menor, aunque envuelto en blandura y molicie confesadas, no alcanza el sensualismo desbordado de su discípulo Meléndez, ni llega a la creación del cuadrito mitológico, aunque esté a veces insinuado:

Una tropa ligera de sátíros y faunos y silvanos impaciente os espera,

24. Refiere el autor los motivos que tuvo para aplicarse a la poesía, y la calidad de los asuntos que tratará en sus versos, y Declara el autor su amor a Filis, BAE, t. 61, ps, 248-249. 
venida de los montes más lejanos, para formar su danza, y lloran tristes ya vuestra tardanza. ${ }^{25}$

Lo que sí es más significativo es el gusto figurativo de los menudos objetos típicos del mundo dieciochesco, aunque lo haga con propósito satírico de contraste:

Ni el paje primoroso,

ni la criada antigua y estimada

un almuerzo suntuoso

presentará en vajilla bien labrada

pero la leche blanca cual tu frente

permitirás mi mano te presente.

Ni polvos, ni pomada,

cintas compuestas, aguas ni alfileres

te ofrece mi morada,

ni espejo, consejero de mujeres;

podrás en un arroyo divertirte,

lavarte, poner flores y vestirte. ${ }^{26}$

Con más evidente intención grotesca, pero dentro de la línea del descriptivismo minucioso que caracteriza la frivolidad setecentista, están escritas las octavas Un currutaco en 1770, atribuidas a Cadalso en la BAE, pág. 267, pero que son, según Glendinning, de Ramírez de Góngora, que completó este mundillo dieciochesco en su Optica del cortejo. En las octavas aparecen el "azul zapatillo», "media calada y de color de nieve», "negro calzón de rico terciopelo", "dijes», "campanillas», "reloj», "chupilla corta, azul y plateada», "verde cutó», "corbatín ajustado» y las "empolvadas sortijas» de "aqueste Adonis».

Sus anacreónticas tienen a veces una ingenuidad picaresca en un rit. mo vivaz y saltarín, como en una donde el poeta se muestra, como Baco,

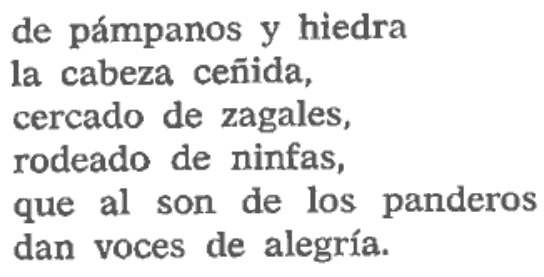

Otras veces, sin morbosidad sensual, el gusto detallista le lleva a componer pequeños retratos femeninos, con un tono de exquisitez y gracia rococo :

25. A los días del excelentisimo señor Conde de Ricla, BAE, t. 61, pág. 252.

26. Carta a Augusta, matrona que inclinada a la filosofia, empieza a fastidiarse de la corte, BAE t. 61 , p. 259 . 


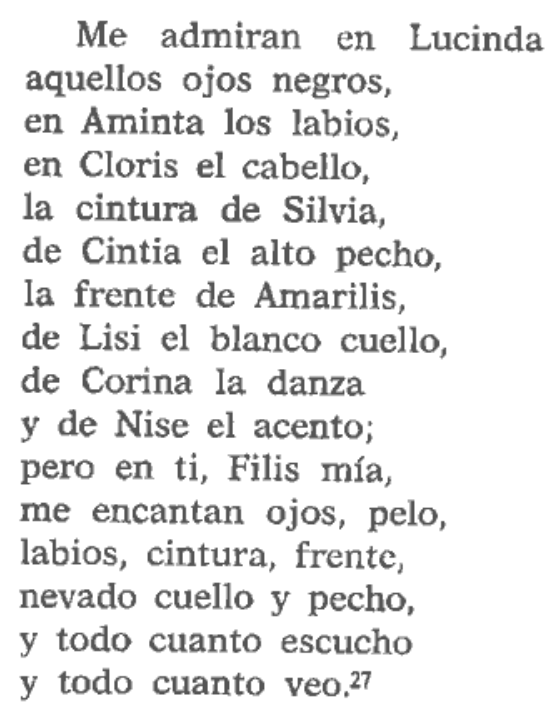

14.- Sintomática me parece, aunque la prudencia aconseja no sacar extremadas consecuencias en este sentido, la relativa innovación métrica atribuible a Cadalso, que consiste en la rima interior en el tercer verso de la clásica estrofa sáfico-adónica. ${ }^{28}$ Aunque Nicolás F. de Moratín haya escrito antes anacreónticas y sáfico-adónicos, según afirma Glendinning, lo cierto es que desde Quintana viene diciéndose que fue Cadalso quien hizo revivir la anacreóntica, que estaba enterrada desde Villegas. Esta consonancia leonina, que da cierto brío a la severa estrofa, sin recargarla con las rimas finales demasiado ostensibles, añade un atractivo asimétrico y caprichoso a la combinación estrófica, muy del arte rococó. Unase a ello, en este caso concreto, la mitología familiar, la predilección por la blancura, la disminución afectiva de los vocablos y la complacencia en motivos ornamentales botánicos, y se tendrá una muestra, entre elegante y frívola, de cómo se hace mórbida la estrofa y graciosamente dieciochesca, adaptando elementos anteriores:

Madre divina del alado niño, oye mis ruegos; que jamás oíste otra tan triste lastimosa pena como la mía. de leche blanca y el de miel sabrosa;

27. Anacreónticas, BAE, t. 61, ps, 272 y 274 respectivamente.

28. Villegas la había empleado saltuariamente en algunas estrofas. En el xviIx es utilizada de modo constante en algunas composiciones por Cadalso, Jovellanos, Iglesias de la Casa, el Conde de Noroña y J. N. Gallego. Que el restaurador fue el propio Cadalso consta en una carta suya a N. F. de Moratín: "La consonancia del segundo verso con la mitad clel tercero es irnitado de Estevan de Villegas y creo que no es importuna salvo meliori sententia qual es la de vmd. a la que me remiton (Revue Hispanique, I, 1894, p. 305). 
ciño con rosa, mirtos y jazmines esta mi frente.

Mi palomita con la blanca pluma, aún no tocada por pichón amante, pongo delante de tu simulacro; no la deseches... ${ }^{29}$

15.-La década del 70, época del apogeo de Cadalso y del paulatino influjo de Jovellanos en la vida pública y literaria - nacidos ambos, con Iglesias, treinta años antes-, es realmente importante en la historia de las corrientes poéticas dieciochescas. De 1773 son los Ocios de mi juventud, el libro de poesías de Cadalso, que señala la dirección inicial de Meléndez Valdés e Iglesias de la Casa. Ellos mismos lo reconocerán públicamente en una carta, escrita a la muerte de Cadalso en 1782:

"A él sólo deben Arcadio y Batilo que las musas les den sus blandas inspiraciones, y Apolo su lira celestial; a él deben que, libres de las nieblas de la ignorancia, busquen la Sabiduría en su Santuario Augusto, $y$ no se contenten con su mentida sombra. $»^{30}$

La poesía de Iglesias está en gran parte situada en la línea tradicional de las letrillas ágiles y humorísticas. Dentro de los temas satíricos y de tono menor, algunos, insistentemente repetidos, como el del marido cornudo, pueden derivarle de Cadalso. Lo que individualiza, sin embargo, a Iglesias es su predilección por los motivos florales y su sentido colorista. Algunas escenitas mitológico-campestres, recortadas y compuestas, están, por tópicas, dentro del gusto que comentamos:

\footnotetext{
Faunos y silvanos los veréis llegar,

Más interesante es su sentido de la naturaleza artificial, hecha jardín galante, con sus mármoles, fuentes y bullir de aguas y espumas, elementos ornamentales del peculiar hedonismo dieciochesco:

De entre mármoles bellos de colores las regaladas fuentes se deslizan,

29. Otros a Venus, BAE, t. 61, p. 266.

30. Carta sin fecha, a la muerte de Cadalso, de «Batilo y Arcadio, zagales del Tormes, a su amado Hormesindo" (Felipe Ximénez de Sandoval, "Quince cartas inéditas del Coronel Cadalson, Hispanófila, núm. 10, 1960, p. 42).

31. Letrilla II. De sus cantares, BAE, t. 61, p. 417. 
y el ámbar usurpándole a las flores,

su líquido cristal aromatizan;

o ya los arroyuelos trepadores

la blanca espuma con primor enrizan,

y en blanda risa y plácido sonido

al corazón alegran y al oído. 32

Sigue también a Cadalso en los sáficos-adónicos de rima interior, que utiliza en la égloga VII y donde vuelve a aparecer la alegre decoración mitológica en un ambiente de suntuosidad y refinamiento, que sitúan el cuadro entre el brío dinámico del detallismo recocó y un sentido de constructividad formal, casi neoclásico, si no fuera por su gracia ondulante:

Por bellos caños de variado jaspe

viertas, oh fuente, perlas orientales,

y en tus cristales los sedientos pechos néctares beban.

Deja tus urnas, regalado Tormes,

y a ver el día sal del agua afuera,

$y$ en tu ribera discantando mira cándidos cisnes.

También vosotros, amorosos Faunos, bellas Napeas, coro de Amadrías

y hermosas Drías, celebrad aquesta selva florida.

Vengan, pues, vengan, las divinas Gracias al gozo ameno de la amiga selva; todo se vuelva dulcedumbre, y todo júbilo sea. ${ }^{33}$

Esta interna tensión de la poesía de Iglesias, que la proyecta fuera de la línea de la poesía tradicional, la lleva a veces a los altos motivos de la Ilustración que, injertados en los recuerdos de nuestra poesía renacentista, han de dar carácter al prerromanticismo lírico. El principio de su Canción primera, La vanidad terrena, funde, como hace también Jovellanos, a Fray Luis de León con los nuevos ideales científicos. Donosamente nos dirá en una letrilla:

Este siglo es pasmo

de virtud extraña;

.........

apártense a un lado;

que quiero al instante

32. Egloga VIII, BAE, t. 61, p. 460.

33. Egloga VII, BAE, t. 61, p. 454. 
hicerme adulante del siglo ilustrado. ${ }^{34}$

Aunque se diga con humor, hay conciencia de lo que pretende significar el nuevo siglo, que también Iriarte llamará del mismo modo:

Oiré, sin tomarme pesadumbres, la desvergüenza pública y notoria de la escuela (que llaman) de costumbres, en el siglo (que llaman) ilustrado, y en una capital de un grande estado. 35

Volviendo a Iglesias y a su abierta disposición hacia las nuevas corrientes de fin de siglo, hay que mencionar también, en las Canciones III y IV, la otra veta prerromántica de lo oriental y bíblico asociada a recuerdos evidentes de Herrera. Es el estilo magnífico de la poesía pindárica que termina prefiriendo el mundo oriental al clásico con grandiosas imágenes de bíblica sublimidad.

16.- Si la prosa prerromántica, sin evidente desarrollo inmediato, tiene principio con Cadalso, la elevada poesía de la Ilustración, que acaba bifurcándose en las corrientes prerromántica y neoclásica, se debe a Jovellanos. No que él fuera el único que sintiera esta exigencia, pero su reconocida autoridad y su influjo en poetas sensibles y receptivos fueron suficientes para cambiar los destinos de la poesía española. Es en la misma trascendental década del 70 al 80, concretamente en 1776, cuando Jovellanos envía a sus amigos salmantinos la epístola que ellos llamaron la Didáctica. No es cosa de volver a contar las circunstancias en que esto tuvo lugar y yo mismo lo he hecho en Jovellanos y la sensibilidad prerromántica. Al incitarles a abandonar los temas frívolos y amorosos para sustituirlos por la exaltación de la patria, de los héroes, del bien y la virtud, la poesía intrascendente, encuadrable en el gusto rococó, deja de ser reconocida como materia exclusiva o predominante del quehacer poético. Sólo en el ámbito de la intimidad o como desahogo de inquietudes juveniles, como ocio o entretenimiento, puede ser admisible. Que la pretensión de Jovellanos no fuera aislada, lo comprueba una carta a él dirigida por Trigueros en 1778, en la que éste le declara que no censura el que alguna vez se trate la materia amorosa y se escriba con dulzura y galantería de estilo, "pero no todo ha de ser Amor; hai cosas más dignas de un buen poeta». ${ }^{36}$

34. Letrilla VI, BAE, t. 61, p. 423.

35. Epistola $111, \mathrm{BAE}$, t. 63, p. 27.

36. La publica Georges Demerson en Don Juan Meléndez Valdés et son temps (1754-1817), Paris, 1961, página 563. 
Lo que el gran escritor asturiano significa como maestro de la generación del prerromanticismo en la historia de la lírica española fue también abordado por mí en el artículo mencionado. La voz más nueva de Jovellanos en el orden poético reside quizás en esa atención a las cosas y a los nombres de las cosas más comunes. Estamos muy lejos del frívolo detallismo rococó; estamos en presencia de una realidad circundante, hecha cosas prosaicas, pero sentidas e interpretadas líricamente. A mil setecientos setenta y tantos debe de pertenecer esa elegía, hasta hace poco desconocida, A la ausencia de Marina, quizá la primera muestra verdaderamente representativa de poesía prerromántica, con sus endecasílabos sueltos, su léxico realista, sus lágrimas abundantes, sus apóstrofes, sus anáforas, su ritmo vibrante, sus exclamaciones e interrogaciones. ${ }^{37}$

17.-Meléndez Valdés, su discípulo, nacido exactamente diez años después que él, es el eje, la clave y la síntesis de toda la poesía setecentista española. Por su capacidad mimética, puede erigírsele en modelo de cualquiera de las actitudes líricas del siglo xvirI. Cierto es que ese estilo menor, que aísla y enfoca los elementos frívolos de la vida dieciochesca encuadrables en el anacreontismo o sensualismo rococó, alcanza el punto culminante con Meléndez. El ha dado la tonalidad definitiva a una naturaleza o a unos seres artificiosamente miniaturizados en forma de cefirillos, fuentecillas, yerbezuelas, arroyuelos, zagalejos, bracitos, ojuelos, amorcitos, avecillas, alitas, etc., ha elegido a los más inocentes representantes del mundo animal - palomas, tortolitas, abejas, mariposas-, ha evocado con complacencia las partes del rostro o de la figura femenina - seno, talle, labios, nariz, frente, cejas-, poniendo en primer plano la gracia de lo minúsculo -lunarcitos, hoyuelos, ricitos-; ha repetido la mitología más elemental —Venus, Amor, Baco- y puesto de relieve las insignificantes superfluidades de la coquetería y galantería setecentistas. Ha logrado un género arquetípico concentrando motivos preexistentes. Véase una muestra bien representativa, al captar la intimidad femenina con todo lo que lleva consigo de exquisitez, de sugerencia sensual evocada por los adornos frívolos o por la refinada decoración de los objetos superfluos:

$$
\begin{aligned}
& \text { Aquí el luciente espejo } \\
& \text { y el tocador, do unidas } \\
& \text { con el placer las Gracias, } \\
& \text { se esmeran en servirla. }
\end{aligned}
$$

37. La dio a conocer G. Demerson en «Quatre poèmes inédits de Jovellanos», en Bulletin Hispaniquc, LVIII, 1956, ps. 36-47. Y aparece por primera vez incluida entre sus obras en Poesías de Gaspar 
Y do esmaltada de oro la porcelana rica del lujo preparados, perfumes mil le brinda; coronando su adorno dos fieles tortolitas, que entreabiertos los picos se besan y acarician.

Allí plumas y flores, el prendido y la cinta que del cabello y frente vistosa en torno gira; ......... . Del cuello allí las perlas, y allá el corsé se mira, y en él de su albo seno la huella peregrina....38

\section{Se comprende perfectamente lo que Cadalso afirma en la LXXXVIII de sus Cartas Marruecas:}

«La invención de un sorbete, de un peinado, de un vestido y de un baile es tenida por prueba matemática de los progresos del entendimiento humano... A esto reduce la nación todo el esfuerzo del entendimiento humano; a un nuevo muelle de coche, toda la matemática; a una fuente extraña y un teatro agradable, toda la física; a más olores fragantes, toda la química; a modos de hacernos más capaces de disfrutar los placeres, toda la medcina; a romper los vínculos de parentesco, matrimonio, lealtad, amistad y amor a la patria, toda la moral y filosofía."

Melchor de Jovellanos, edición critica, prólogo y notas de José Caso González, Oviedo, Instituto de Estudios Asturianos, 1961. Caso la fecha ah. 1770». He hecho un análisis de la misma en un artículo periodístico, «Notas a una poesía desconocida de Jovellanos», en El Comercio, Gijón, 15-8-1959.

38. Oda VII, El gabinete, BAE, t. 63, p. 117. Véase también, entre las muchas representativas, la Oda XLII, El abanico, ibíd., p. 103, verdadero cuadrito de época, lleno de malicia y desenfado juguetón, hecho de toques rápidos y breves.

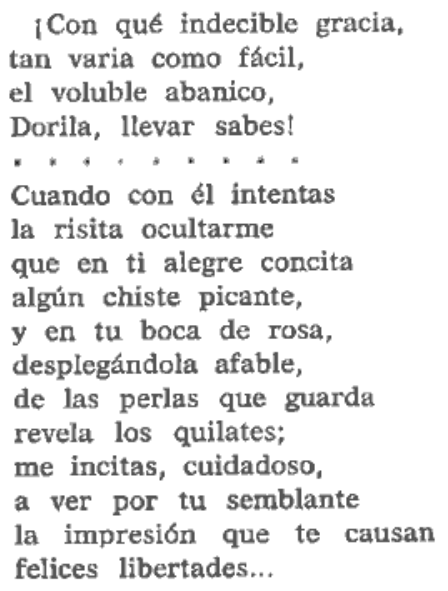


Pues bien, de la poesía rococó se pasa la poesía de la Ilustración cuando el progreso, las matemáticas, la física y la química, la filosofía y la moral, se sienten con todo el alcance que les es propio y no se limitan a la exaltación de los aromas, placeres, objetos, peinados, vestidos e infidelidades.

Este cambio de perspectiva cultural y artística es patente en Meléndez, que eleva también su tono y logra compendiar todas las inquietudes de la poesía posterior. A veces alcanzará una serena compostura, un vocabulario selecto y una entonación digna que le llevan al neoclasicismo. Pero lo normal en él será la ruptura de la forma, la violencia expresiva, el dolor y el tedio como temas, la noche melancólica, el grito de la humanidad desvalida, la proclamación discursiva en nombre del Bien y la Virtud. En Meléndez se da, pues, todo el prerromanticismo formal y temático que, iniciado en la década del 70 , producirá sus frutos más representativos en las dos décadas finales del siglo. Lo que no es obstáculo para que en él se den también muestras arquetípicas de poesía rococó, ilustrada y neoclásica.

18.-El Neoclasicismo, es decir, la culminación de toda la tendencia clasicista y racionalista que ha caracterizado la centuria, coincide en su aparición con el auge prerromántico. Se vuelve a las formas métricas de la tradición italiana, como contraste con el nuevo sentido rítmico, prolongado, anhelante, entrecortado del prerromanticismo lírico, que se vierte en estrofas de estructura abierta y en versos sin rima. El Neoclasicismo está en relación con la difusión de los principios de Winckelmann, para quien la belleza ideal es perfecta armonía de forma en expresión sublime, manifestada en rostros que expresan un equilibrio de sensibilidad. En las obras de Mengs, publicadas en español por Azara en 1780, y de nuevo en 1797, se afirma que "la belleza es la idea o imagen de la perfección posible». Y Ceán Bermúdez, en su Diccionario Histórico, dedicado a las Bellas Artes, asegura en 1800 que con Mengs, muerto en 1779 , vuelve a aparecer "la belleza ideal y otras sublimes partes». En 1784 se expuso en Roma la obra del pintor francés David titulada el Juramento de los Horacios. La afluencia y el fervor público fueron extraordinarios ante un cuadro que representa una completa revolución: los valores típicamente pictóricos se ven sustituidos por una grandeza monumental y una sobriedad expresivas completamente nuevas. No hay planos de profundidad ni tonalidades tenues; hay gestos estatuarios que sugieren una actitud ética y heroica en los personajes. En 1789, Arteaga habla de las condiciones que debe reunir la forma poética para obtener la suprema armonía y dignidad de la elocución en la 
búsqueda de la belleza ideal. Establecerá también una diferencia entre la copia y la imitación, ya que aquélla consiste en reproducir con exactitud el objeto, mientras en ésta hay tan sólo la «semejanza de que es capaz la materia o instrumento en que trabaja». Lección que aprovecha Leandro F. de Moratín y que aplica al juzgar las poesías de Francisco Gregorio de Salas: "Copió en sus obras la naturaleza; pero no la imitó no supo hermosearla.» Y el propio Moratín, en el epitafio que compuso para el mismo poeta, a quien admira por su humildad y sencillez, dirá con neoclásica dignidad, en acertada distribución de períodos rítmicos $\mathrm{y}$ en perfecto equilibrio sentimental y formal:

Amaba la virtud, amó las selvas.

Dióle su plectro, y de olorosas flores

guirnalda le ciñó, la que preside

al canto pastoril, divina Euterpe ${ }^{39}$

Abre Moratín hijo la década de 1760 al nacer en este mismo año. Y los demás verdaderos neoclásicos nacerán todos a partir del último trentenio del siglo: Arriaza, Quintana, Lista, Cabanyes - que representa la culminación de este estilo y inace en el mismo año que Espronceda!y hasta Martínez de la Rosa en parte de su lírica y en los mejores trozos, arquetípicos de la forma poética neoclásica, de su Poética (1827).

19.-La culminación, en cambio, e inmediata disolución del prerromanticismo lírico es algo anterior. Los poetas que le caracterizan en sus formas extremas son Cienfuegos y Francisco Sánchez Barbero, nacidos ambos, sintomáticamente, en el mismo año, 1764. He tratado de estudiar el nacimiento de estas corrientes poéticas a mediados de siglo y no queda tiempo para abordar su efectivo desarrollo posterior. Pero, para terminar, me parecen imprescindibles algunas notas sobre el espíritu poético que caracteriza la madurez de la modalidad prerromántica. Ya desde principios del siglo xIx fue notada la novedad y extremosidad de Cienfuegos. Exaltado por los liberales de entonces, fue, por contraste, execrado en los ambientes oficiales de la cultura, que era, a fines de siglo, de signo neoclásico. Los críticos del xIx suelen unirle a Quintana. Pero Quintana, que algo heredó de él, tenía una robusta formación de tipo clásico que le impide caer en los excesos verbales de aquél, aunque ideológicamente le era muy afín. El juicio que de Cienfuegos dio el propio Quintana es definitivo:

«Nadie le excede en fuerza y en vehemencia, y no sería mucho decir que tampoco nadie le iguala. Aunque el fondo de ideas sobre que su

39. BAE, t, II, ps. 615 y 606 respectivamente. 
imaginación se ejercita pueda decirse tomado de la filosofía francesa, no ciertamente el tono ni el carácter, que guardan más semejanza con la poesía osiánica y con la poesía alemana. Pero si el estilo, por llevar el sello robusto y fogoso de su índole y de su ingenio, se hacía respetar de los lectores, no así la dicción a que daban cierto aire de afectación y extrañeza el uso excesivo de palabras compuestas, los arcaísmos poco necesarios y sobre todo las frases y palabras inventadas por el escritor y usadas por su autoridad particular., $\$ 0$

También Larra trata de justificarle de la inculpación de haber respetado poco la lengua:

"¿Qué mucho -escribe--, si Cienfuegos era el primer poeta que teníamos filosófico, el primero que había tenido que luchar con su instrumento y que le había roto mil veces en un momento de cólera o de impotencia.?»41

Una vez más, los más cercanos habían visto bien: toda la importancia de Cienfuegos en la historia de la lírica española reside en su intento por crear una lengua poética, intento fallido e infructuoso, pero no de menor alcance linguiístico que el que, más de un siglo después, lograría Rubén Darío. Nada tiene de extraño que le hayan perseguido con saña los estreñidos críticos ochocentistas que confundían la dignidad de la forma neoclásica con su estrechez de miras y de gusto: ejemplo de ello son Tíneo y Gómez Hermosilla. La modalidad de Cienfuegos fue por entonces calificada de neogongorismo en su aspecto formal y de panfilismo o filosofismo en su aspecto temático. Cuestión de nombres, naturalmente, pero lo importante es señalar los límites perfectamente definidos del movimiento prerromántico, cuya existencia como grupo o, mejor, como tendencia o corriente, no puede negarse. Para no repetir nociones ya tratadas por otros, ${ }^{42}$ me atendré exclusivamente a la lengua. La novedad más llamativa, por su reiterado empleo, consiste en la normal ruptura de la relación de sentido existente en el sintagma nombreadjetivo, que se sustituye por otro equivalente trasmutando las funciones de ambos componentes y alterándose, por tanto, la relación de dependencia entre el término primario y el secundario. Quizá podría afirmarse que, en contraste con el sentido lineal y macizo de la expresión neoclásica, hay aquí un intento pictórico de sustituir las cosas por la sustantivación de sus cualidades. Véase el paso de la expresión normal a la usada por Cienfuegos, que es la última: selvas espesas=la espesura de

40. M. J. Quintana, ob. cit., pág. XLVI.

41. M. J. de Larra, "Literatura», en Artículos de critica literaria y artística, Madrid, Espasa-Calpe, 1940, ps. $165-166$.

42. Juan Ruiz Peña, «La inflamada voz de Cienfuegos», Escorial, t. XIV, 1944. J, Luis Cano, "Cienfuegos, poeta social», en Papeles de San Armadans, VI, 1957. 
las selvas=las selvosas espesuras. $\mathrm{Y}$ por el mismo camino se llega al hojoso verdor, musgoso verdor, selvoso frescor, letargoso olvido, nublosa oscuridad, aspereza montañosa, para culminar en y ya anegada con salobre muerte o la nevosa altivez del Guadarrama. Como se ve, la extravagancia de la expresión, igual que le ha de ocurrir a Sánchez Barbero, puede llegar a rozar lo grotesco. Aunque no sean exactamente del mismo tipo, véanse expresiones afines: enriscada costa, añosa maldad, invernal tristeza, hermanal familia, hambre macilenta, pampanoso octubre, acentos ladradores, enlutada luna, congojosa choza...

Otra novedad de la lengua de Cienfuegos - novedad relativa, ya que es Meléndez, sobre todo, quien insinúa estas creaciones o restauraciones lingüísticas, satirizadas por Moratín, es la abundancia de participios de presente no usuales: el eco retumbante, el espumante caballo, las bramantes olas, alondras revolantes, vivificante sol, el abismo hondi-tronante del Etna, león que centelleante, rugiente compañero, silencio amante, vid doliente...

20.-En la misma línea está, aunque nunca se le recuerda en este sentido, Francisco Sánchez Barbero. En algunos puntos hasta exagera la lección de Cienfuegos. Los temas autobiográficos, patrióticos, carcelarios y patibularios, sociales y bíblicos, se expresan en un lenguaje bronco, obsesivo, balbuciente. A la ostentación retórica de lo estruendoso y trepidante pertenecen versos como

el polo al ronco estruendo con que los truenos sin cesar retumban,

no vacilando en llegar a decir, en otra ocasión, estrépito ruidoso. Todos los recursos son válidos para obtener determinados efectos:

Era diciembre; deslunada noche, cargado el éter de pluviosas nubes.

No sólo hablará de el enlutado escriba, sino también de enlutado duelo. Por este camino llegará incluso, tras la noche deslunada, a la noche enlutecida.

21.-El prerromanticismo supone una forma poética abierta, una lengua personal y una temática ligada a los ideales humanitarios, sociales, políticos y hasta jurídicos de entonces. En abierta oposición, sobre todo formal, más que ideológica, se perfila la poesía neoclásica. Ya para terminar, puede leerse el prólogo que Juan Bautista Arriaza puso a sus poesías en 1807, donde, al precisar su ideal poético, define también una vez más, por contraste, los caracteres de la poesía prerromántica: 
«No puede haber verdadera expresión de ideas en donde no reine la mayor claridad de dicción; [...] que esta claridad debe ir siempre acompañada de una constante elegancia en el decir; pero que esta elegancia no consiste en una sucesión de inversiones gramaticales, de tantos adjetivos retumbantes, ni de tanta metáfora de metáfora, a lo que algunos dan el nombre de lenguaje poético, atribuyendo a misterios del arte su falta de claridad [...] Pero de muy pocos años a esta parte se hace alarde entre nosotros de llamar pueril y bárbaro este mecanismo [la rima], sin otra razón que la misma dificultad que ofrece a los que quisieran se les abriese el Parnaso por sólo los méritos de eruditos o filósofos $[\ldots]$ ¿..Y qué diremos si a la sequedad del verso suelto aún pretendiese agregar cierto estilo declamatorio, un tono sentencioso, un empeño en derramar la moral cruda, con exclusión de los mitológicos adornos y de las invenciones alegóricas? [...] La práctica de estos principios [...] me ha parecido ser semilla de una nueva secta, que sucederá a las dos ya desterradas y conocidas con los nombres de culteranismo y conceptismo, la cual vendremos a llamar filosofismo; tanto más hermana de ellas, cuanto se compone de los mismos elementos, que son hinchazón y oscuridad.»43

22.- Si unas conclusiones provisionales fueran necesarias, habría que admitir que muestras de poesía correspondientes al gusto rococó y a los altos ideales de la Ilustración, se dan contemporáneamente en España a mediados del siglo xviri. Lo que coincide casi, en el último cuarto de ese siglo, son las corrientes prerromántica y neoclásica. Es más, ésta nace conscientemente un poco después y perdurará mucho más. Aquélla, en cambio, que no corresponde a una estética definida, que es útil reconocerla para agrupar aislados y hasta incoherentes intentos revolucionario, se agota, apenas avanzado el siglo XIX, por el carácter transitorio y de subordinación que se da al vocablo "prerromántico». Lo cual no quiere decir, entiéndase bien, que esos caracteres precursores o de anticipación se insinúen de manera lenta y gradual. Lo típico del prerromanticismo, al menos del nuestro, es su virulencia y su énfasis, sus excesos incontrolados, a los que no han de llegar los más calificados poetas románticos cuando repitan, sin saberlo, motivos y formas tratados ya medio siglo antes. $\mathrm{Y}$ debe asimismo tenerse en cuenta que, si nuestro romanticismo llega con retraso, no puede afirmarse lo mismo del movimiento prerromántico.

Otra conclusión a la que puede llegarse es de orden estilístico o de caracterización de géneros. Si la preocupación clásica -y, por tanto, la neoclásica- es la de delimitar y distinguir, evitando la confusión en las formas artísticas, la tendencia de los prerrománticos, sin duda instintiva,

43. BAE, t. 67, v. 46 
es la de acortar distancias entre las formas y los géneros literarios. Por eso, mientras la prosa prerromántica busca cadencias evocadoras en una periodización formal de base rítmica, la poesía tiende a los párrafos amplios, al verso suelto, a estrofas sin autonomía musical. En otras palabras, a una poesía conscientemente "prosaica», densa de ideas y de ideales humanitarios, corresponde una prosa rebuscadamente "poética». Indeterminación de límites, en la que no cae jamás el verdadero neoclásico. 